\title{
Leaching of Fluoride from Biotite Mica in Soil: Implications for Fluoride in Shallow Groundwater
}

\author{
K. U. K. S. Kularatne and H. M. T. G. A. Pitawala \\ Department of Geology, Faculty of Science, University of Peradeniya, 20400 Peradeniya, Sri Lanka \\ Correspondence should be addressed to H. M. T. G. A. Pitawala, apitawala@pdn.ac.lk \\ Received 15 December 2011; Accepted 17 January 2012 \\ Academic Editors: V. Ferro and L. S. van Overbeek
}

Copyright $\odot 2012$ K. U. K. S. Kularatne and H. M. T. G. A. Pitawala. This is an open access article distributed under the Creative Commons Attribution License, which permits unrestricted use, distribution, and reproduction in any medium, provided the original work is properly cited.

Leaching of $\mathrm{F}^{-}$from biotite was investigated at room temperature by performing a series of short-term leach tests. The leaching of $\mathrm{F}^{-}$from biotite structure strongly depends on its weathering stage. Results of this study suggest that high concentration of $\mathrm{F}^{-}$is leached from highly weathered biotite, compared to fresh biotite. Results of dissolution experiments confirm that the organic acids in soil promote the leaching of $\mathrm{F}^{-}$from biotite compared to inorganic acids. Citric acid which is a week organic acid enhances leaching of $\mathrm{F}^{-}$from biotite structure compared to strong inorganic acid $\mathrm{HNO}_{3}$, independent of the weathering stage of biotite. Strong positive correlation between $\mathrm{K}^{+}$and $\mathrm{Fe}^{2+}$ with $\mathrm{F}^{-}$in biotite treated with citric acid suggests that $\mathrm{F}^{-}$readily leachs into the solution through an ionic exchange and complex formation. Organic acids involve sorption and complex formation processes leading to release of $\mathrm{F}^{-}$into the solution. Our studies suggest that in the presence of organic acids $\mathrm{F}^{-}$is leached readily into water percolating through the soil. Therefore, shallow groundwater replenished by the water table may achieve high $\mathrm{F}^{-}$concentrations by this leaching process.

\section{Introduction}

Biotite contributes up to $3400 \mathrm{ppm}$ of fluoride in ground water [1]. The high fluoride concentrations in groundwater in metamorphic terrains are due to the dissolution of biotite, which may contain significant fluorine at the $\mathrm{OH}$ sites of their octahedral sheet [2-4].

Biotite has been observed to alter into other sheet silicates, depending on the alteration conditions [5], and in particular, to chlorite, vermiculite, and kaolinite [6]. Interstratifications of vermiculite or kaolinite with biotite usually occur, indicating structural inheritance from the primary mineral [7], because of a similarity in crystal structure between the primary stage and the secondary clay structure. These clay minerals also act as sources for fluoride in the soil [8]. Clay minerals show good anion exchange capacity, and therefore, large amounts of fluoride can retain in the soils under neutral $\mathrm{pH}$ conditions [9]. Widespread occurrence of biotite in surface crustal rocks and the relatively high reactivity of biotite in the weathering environment indicate that the dissolution kinetics of biotite is likely to be important in the assessment of watershed geochemical processes.

The literature describing experimental studies of rates and mechanisms of precipitation and dissolution of minerals is voluminous. Much experimental work on the kinetics of solution-mineral reactions has focused on silicate [1013] and $\mathrm{Ca}-\mathrm{Mg}$ carbonate minerals [14-16]. Although the kinetic properties and dissolution rates of biotite mica have also been investigated [17-21], leaching of $\mathrm{F}^{-}$from biotite under natural conditions has been much less investigated.

Leach experiments of biotite with respect to its weathering stage and different acidic conditions can be used to understand its potential to release fluoride into soil and its contribution towards the accumulation of fluoride into groundwater table. The present study is focused to understand the behavior of fluoride in biotite under different acidic media in order to interpret the release of fluoride from 
TABLe 1: Physical and optical properties of biotite samples.

\begin{tabular}{|c|c|c|c|}
\hline Sample & Weathering intensities & Appearance properties & Optical properties \\
\hline M1 & Highly weathered & $\begin{array}{l}\text { Light brown color, highly disintegrated } \\
\text { material. }\end{array}$ & $\begin{array}{l}\text { About } 50 \% \text { of chlorite is present. Optical and } \\
\text { physical properties of typical biotite grains are } \\
\text { lacking. }\end{array}$ \\
\hline M2 & Moderately weathered & $\begin{array}{l}\text { Light brown color, highly altered along } \\
\text { cleavage. }\end{array}$ & $\begin{array}{l}\text { Slightly disintegrated biotite crystals show pale } \\
\text { yellow under the plane polarized light. About } 25 \% \text { of } \\
\text { chlorite is present as interstratified alteration } \\
\text { products. }\end{array}$ \\
\hline M3 & Moderately weathered & Black color. Less altered along cleavage. & $\begin{array}{l}\text { Pale yellow under the plane-polarized light. } \\
\text { Considerably large amount of pale green chlorite is } \\
\text { present as patches along the cleavages and as } \\
\text { interstratified alteration products. }\end{array}$ \\
\hline M4 & Moderately weathered & $\begin{array}{l}\text { Black color. Slightly altered along grain } \\
\text { boundary. }\end{array}$ & $\begin{array}{l}\text { Pale green patches of chlorite present along the grain } \\
\text { boundaries and basal surfaces are smooth, and } \\
\text { cleavages are visible. }\end{array}$ \\
\hline M5 & Fresh & $\begin{array}{l}\text { Dark greenish black color altered } \\
\text { hexagonal plates. }\end{array}$ & $\begin{array}{l}\text { No alterations within grains or along cleavages. The } \\
\text { color under plane-polarized light varies between } \\
\text { yellow, dark brown, and green. Yellow and brownish } \\
\text { green pleochroism mottled appearance when the } \\
\text { mineral is close to the extinction position. Free of } \\
\text { inclusions. }\end{array}$ \\
\hline
\end{tabular}

fresh, moderately weathered, and highly weathered biotite in micaceous soils and rocks.

\section{Materials and Method}

Considering the weathering conditions, five biotite samples were collected from Owala pegmatite body at Matale in the North Central Sri Lanka, where inclusion-free biotite is available. The pegmatite body is located in hilly area and is currently being mined for feldspar. Each sample was collected from central parts of mica-rich zones in the mine where the accumulated leachates from the surroundings are minimal. These samples include fresh, moderately weathered, and highly weathered biotite with different physical and optical properties (Table 1). Biotite samples were numbered as M1 (highly weathered), M2, M3, M4, and M5, in order for decreasing intensity of weathering. Chemical composition of fresh biotite used for this study is given in Table 2. Weathering intensities of minerals and mineralogical changes in the treated samples were studied by optical means and X-ray diffraction analysis using Seimens D-5000 diffractometer at the Department of Chemistry, University of Peradeniya, Sri Lanka.

Powdered biotite $(53-63 \mu \mathrm{m}$ size fraction) samples (40.0 g) were moistened separately with distilled water, citric acid $(0.1 \mathrm{M})$, and nitric acid $(0.1 \mathrm{M})$ assuming that these solutions can stimulate natural conditions. The moisture content and $\mathrm{pH}$ of each sample were maintained by adding equal amounts of appropriate reagents when necessary. The $\mathrm{pH}$ of samples treated with distilled water, citric acid, and nitric acid were 6, 2.2, and 1, respectively. Experiment was carried out under room temperature $\left(25^{\circ} \mathrm{C}\right)$, and it did not vary much during the study period. Variation of available fluoride and cations of treated samples were measured with time. Concentration of $\mathrm{F}^{-}$in the filtrates
TABle 2: Major and minor element composition of two representative fresh biotite samples and average chemical composition [22]; LOI: lost on ignition, n.d: not detected.

\begin{tabular}{lccc}
\hline Element oxide wt\% & SL 23 & SL 26 & Average $(n=8)$ \\
\hline $\mathrm{SiO}_{2}$ & 45.43 & 44.12 & 44.35 \\
$\mathrm{Al}_{2} \mathrm{O}_{3}$ & 34.86 & 33.95 & 34.56 \\
$\mathrm{Fe}_{2} \mathrm{O}_{3}$ & 1.81 & 1.78 & 1.73 \\
$\mathrm{MnO}$ & 0.01 & 0.02 & 0.01 \\
$\mathrm{MgO}$ & 0.69 & 0.76 & 0.81 \\
$\mathrm{CaO}$ & n.d & n.d & - \\
$\mathrm{Na}_{2} \mathrm{O}$ & 0.70 & 0.70 & 0.35 \\
$\mathrm{~K}_{2} \mathrm{O}$ & 10.22 & 9.98 & 9.87 \\
$\mathrm{TiO}_{2}$ & 0.37 & 0.36 & 0.35 \\
$\mathrm{P}_{2} \mathrm{O}_{5}$ & 0.03 & 0.78 & 0.43 \\
$\mathrm{LOI}$ & 4.82 & 6.28 & 5.98
\end{tabular}

was analyzed using SPADNS spectrophotometric method using the HATCH DREL 12400 spectrophotometer. $\mathrm{Na}^{+}, \mathrm{K}^{+}$, $\mathrm{Mg}^{2+}$, and $\mathrm{Fe}^{2+}$ cations were measured on the Parkin-Elmer 2800 atomic absorption spectrophotometer (AAS) at the Analytical Laboratory, Department of Geology, University of Peradeniya, Sri Lanka. All batch incubation procedures were done in triplicates, and the experiment was continued for six months.

\section{Results}

3.1. Leaching of Ions with Respect to the Weathering Conditions. All types of biotite treated with citric acid released considerably higher amounts of $\mathrm{F}^{-}$after six months of incubation compared to those treated with nitric acid and distilled water (Figure 1(a)). The measured $\mathrm{F}^{-}$values of mica 
TABLE 3: Leachable ionic concentrations of treated fresh biotite: after one month and six months.

\begin{tabular}{|c|c|c|c|c|c|c|}
\hline \multirow{3}{*}{ Ions } & \multicolumn{6}{|c|}{ Medium } \\
\hline & \multicolumn{2}{|c|}{ Citric acid } & \multicolumn{2}{|c|}{ Nitric acid } & \multicolumn{2}{|c|}{ Distilled water } \\
\hline & 1st month & 6th month & 1st month & 6th month & 1st month & 6th month \\
\hline $\mathrm{F}^{-}$ & 1980 & 9000 & 450 & 2900 & 150 & 2600 \\
\hline $\mathrm{K}^{+}$ & 1677 & 4521 & 2634 & 4236 & 378 & 460 \\
\hline $\mathrm{Fe}^{2+}$ & 1000 & 5215 & 2007 & 2400 & 27 & 71 \\
\hline $\mathrm{Mg}^{2+}$ & 239 & 756 & 276 & 346 & 53 & 36 \\
\hline $\mathrm{Na}^{+}$ & 130 & 230 & 130 & 271 & 63 & 98 \\
\hline
\end{tabular}

TABLE 4: Leachable ionic concentrations of treated highly weathered biotite: after one month and six months.

\begin{tabular}{|c|c|c|c|c|c|c|}
\hline \multirow{3}{*}{ Ions } & \multicolumn{6}{|c|}{ Medium } \\
\hline & \multicolumn{2}{|c|}{ Citric acid } & \multicolumn{2}{|c|}{ Nitric acid } & \multicolumn{2}{|c|}{ Distilled water } \\
\hline & 1st month & 6th month & 1st month & 6th month & 1st month & 6th month \\
\hline $\mathrm{F}^{-}$ & 1980 & 9000 & 2700 & 5750 & 300 & 3150 \\
\hline $\mathrm{K}^{+}$ & 1091 & 1216 & 1277 & 390 & 68 & 65 \\
\hline $\mathrm{Fe}^{2+}$ & 2008 & 5320 & 1031 & 1262 & 9 & 29 \\
\hline $\mathrm{Mg}^{2+}$ & 170 & 613 & 225 & 369 & 75 & 73 \\
\hline $\mathrm{Na}^{+}$ & 157 & 295 & 181 & 274 & 132 & 213 \\
\hline
\end{tabular}

treated with citric acid were 2-3 times higher than those of others. Also it was revealed that content of releasable $\mathrm{F}^{-}$in highly weathered biotite mica was considerably high (average up to $9000 \mathrm{ppm})$. In contrast, fresh and moderately weathered biotite is characterized by lower amounts of leachable $\mathrm{F}^{-}$, and all types have almost comparable concentrations.

Unlike the behavior of $\mathrm{F}^{-}$, the highest amount of $\mathrm{K}^{+}$ has been released from the fresh biotite, whereas highly weathered biotite released the lowest quantity (Figure 1(b)). However, citric acid is again the main agent for releasing $\mathrm{K}^{+}$. Compared to the measured $\mathrm{F}^{-}$values, released $\mathrm{K}^{+}$ concentrations of the samples were low (<4000 ppm).

Variation pattern of leaching of $\mathrm{Fe}^{2+}$ from treated biotite is almost similar to that of $\mathrm{K}^{+}$(Figure $1(\mathrm{c})$ ). The results show that the release of $\mathrm{Fe}^{2+}$ also depends on the type of treated medium. Out of the measured cations, $\mathrm{Na}^{+}$and $\mathrm{Mg}^{2+}$ do not show a considerable change with the weathering stage or the type of acid, and their concentrations do not vary considerably with time.

3.2. Comparison of Leaching with Respect to the Time. The measured data show that leachable $\mathrm{F}^{-}$and $\mathrm{K}^{+}$concentration of fresh biotite treated with citric acid is distinctly high after 6 months of incubation (Table 3). The differences between the initial and final concentrations of $\mathrm{F}^{-}$and $\mathrm{K}^{+}$are around $7000 \mathrm{ppm}$ and $2871 \mathrm{ppm}$, respectively. These differences are much higher compared to values obtained for treated fresh biotite with distilled water $(<2300 \mathrm{ppm})$. Unlike variation of $\mathrm{F}^{-}$and $\mathrm{K}^{+}$during the treatment period, the variation of leachable $\mathrm{Fe}$ is not marked, and the pattern of variation is almost flat for most of samples.

Table 4 compares the initial and final ionic concentrations of treated highly weathered biotite (M5). A high difference between the initial and final concentrations of $\mathrm{F}^{-}$ was shown by biotite treated with citric acid (7120 ppm), whereas it is least in biotite treated with distilled water $(2850 \mathrm{ppm})$. Similarly, there is a considerable difference between the initial and final concentrations of $\mathrm{K}^{+}$in biotite treated with citric acid (125 ppm), while it is least in biotite treated with distilled water ( $3 \mathrm{ppm})$.

In contrast to the variation of $\mathrm{Fe}^{2+}$ in fresh biotite, the difference between final and initial concentrations of $\mathrm{Fe}^{2+}$ in biotite treated with citric acid is considerably high $(3320 \mathrm{ppm})$. The concentrations of $\mathrm{F}^{-}$(Figure $\left.1(\mathrm{~d})\right), \mathrm{K}^{+}$ (Figure 1(e)), and $\mathrm{Fe}^{2+}$ (Figure 1(f)) of fresh biotite treated with citric acid increase with time. However, rapid rate of increase was noted after four months. Also it is noted that the variation patterns of all ions were comparable. The variation of $\mathrm{F}^{-}, \mathrm{Fe}^{2+}$, and $\mathrm{K}^{+}$in the extracts of biotite treated with citric acid with time is similar. In contrast, they do not vary as such in biotite treated with nitric acid or distilled water. The concentration of $\mathrm{F}^{-}$leached from treated fresh biotite increases gradually with time. However, the highest rate of leaching of $\mathrm{F}^{-}$is observed in biotite treated with citric acid. A rapid rate of increase of $\mathrm{F}^{-}$was noted after four months of treatment (Figure $1(\mathrm{~d})$ ).

3.3. Pearson Correlation. There is a strong positive correlation among $\mathrm{K}^{+}, \mathrm{F}^{-}$, and $\mathrm{Fe}^{2+}$ in the extracts of biotite treated with citric as shown in Table 5 . The correlation coefficients ( $\mathrm{R}$ ) between $\mathrm{Fe}^{2+}$ and $\mathrm{F}^{-}, \mathrm{K}^{+}$and $\mathrm{F}^{-}$, and $\mathrm{K}^{+}$and $\mathrm{Fe}^{2+}$ are $0.5019,0.5138$, and 0.5413 , respectively. This relationship is not obtained for biotite treated with distilled water, or $\mathrm{HNO}_{3}$.

3.4. Mineralogical Changes. X-ray diffraction (XRD) analysis showed that there were no mineralogical and structural changes in (i) all types of biotite treated with nitric acid 


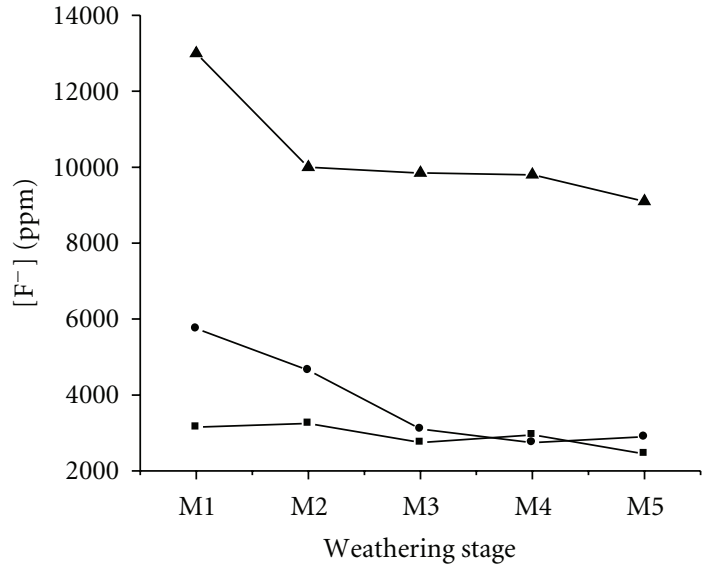

(a)

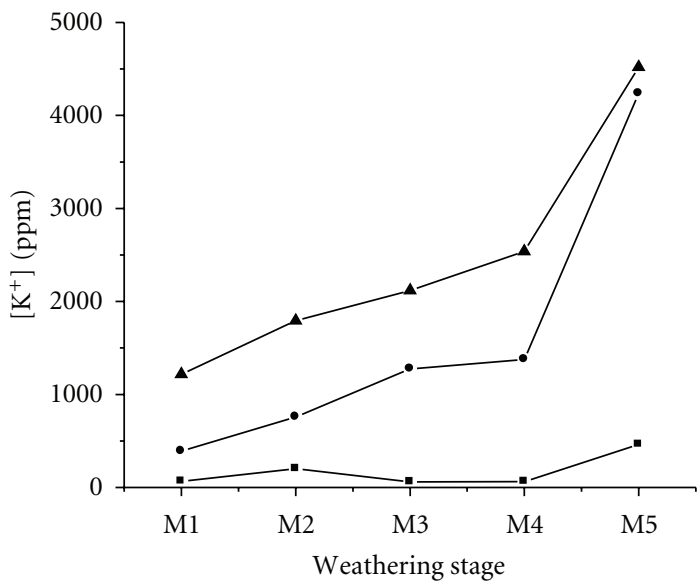

(b)

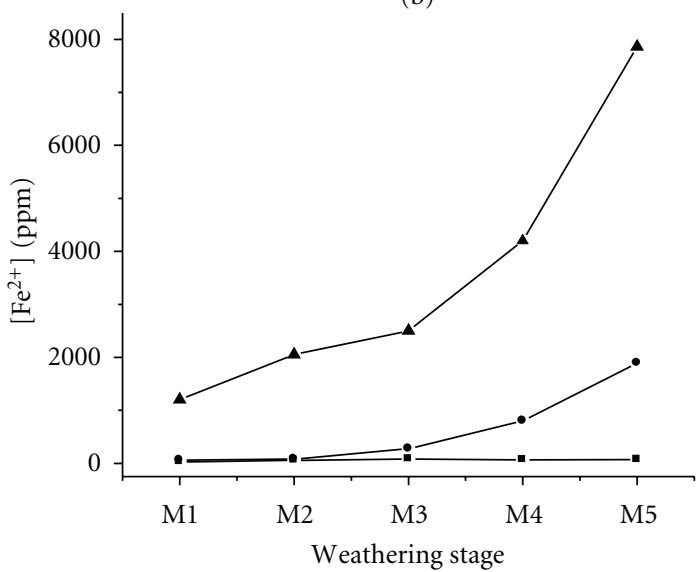

A Biotite treated with citric acid

- Biotite treated with nitric acid

- Biotite treated with distilled water

(c)

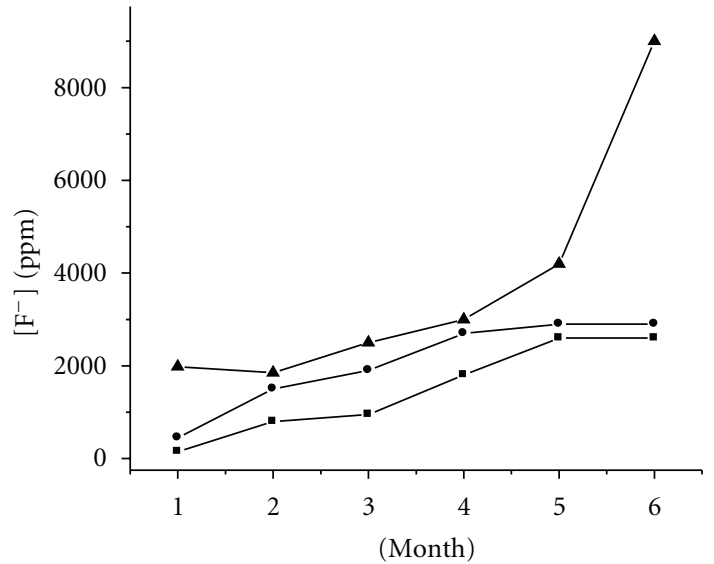

(d)

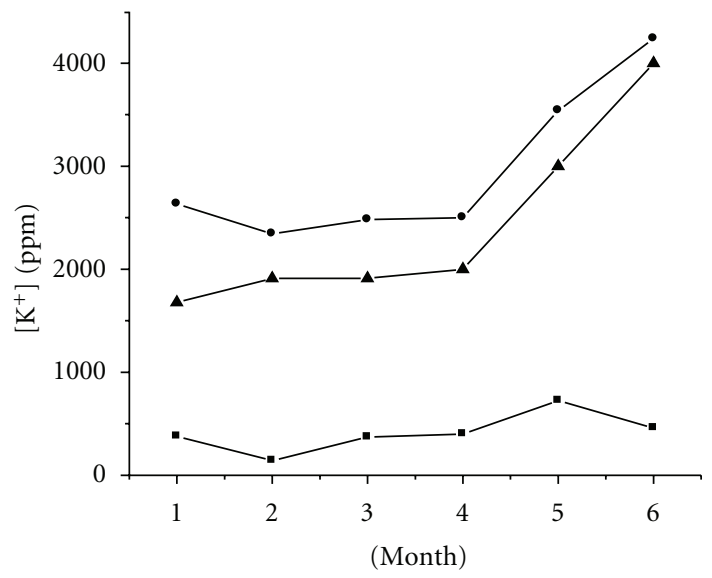

(e)

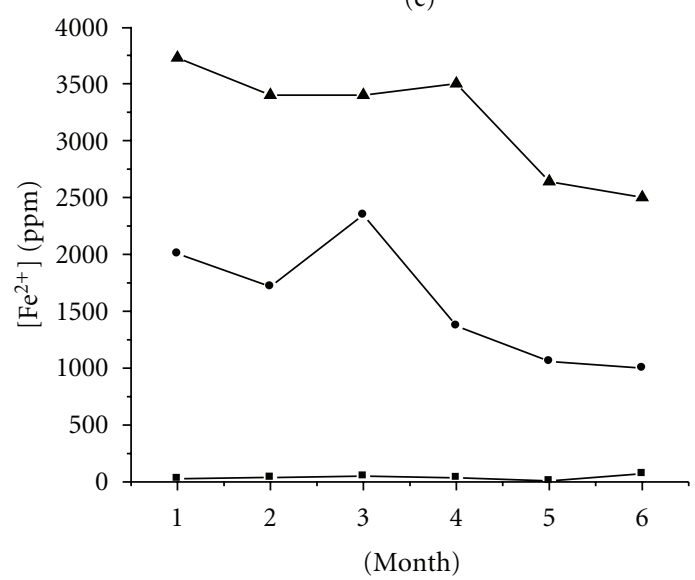

- Biotite treated with citric acid

- Biotite treated with nitric acid

- Biotite treated with distilled water

(f)

Figure 1: Variation of available (a) $\mathrm{F}^{-}$, (b) $\mathrm{K}^{+}$, and (c) $\mathrm{Fe}^{2+}$ in treated mica according to weathering stage, and leaching rate of (d) $\mathrm{F}^{-}$, (e) $\mathrm{K}^{+}$, and (f) $\mathrm{Fe}^{2+}$ from fresh biotite. 


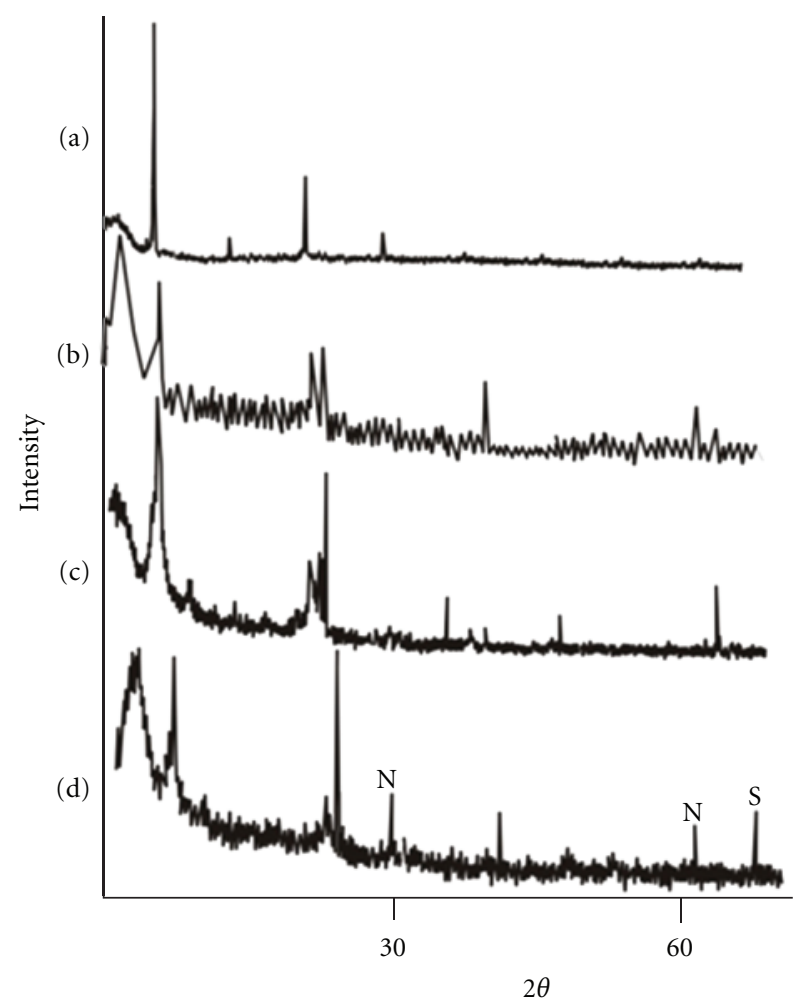

FIGURE 2: XRD pattern of fresh biotite treated with (a) untreated fresh biotite, (b) highly weathered biotite treated with distilled water, (c) $\mathrm{HNO}_{3}$ acid, and (d) citric acid. Note: $\mathrm{N}$ : new peaks, $\mathrm{S}$ : shifted peaks.

and water and (ii) fresh biotite treated with citric acid. In contrast, structural changes were obtained in highly weathered biotite treated with citric acid (Figure 2). Appearance of new peaks and shifting and disappearance of previous peaks confirm the structural changes in weathered biotite.

\section{Discussion}

4.1. Influence of the Structure of Biotite on Leaching of $\mathrm{F}^{-}$, $\mathrm{K}^{+}$, and $\mathrm{Fe}^{2+}$. XRD analysis revealed that the samples used in this study are pure samples unlike most of biotite which may contain numerous inclusions such as zircon, magnetite, titanite, wolframite, apatite, and rutile. Therefore, it is very clear that the measured leached ions are only from the biotite structure.

During weathering of biotite, the structural transformation initially takes place due to loss of interlayer $\mathrm{K}^{+}$ which is compensated by an intake of hydrated exchangeable cations [23]. The transformation can take place by layer weathering or by edge weathering [24]. In layer weathering, some interlayers are "opened" throughout the crystal that facilitates to replace $\mathrm{K}^{+}$by hydrated exchangeable cations. As the $\mathrm{K}^{+}$is highly mobile element, the leached ions remove from the biotite structure. Therefore, highly weathered biotite contains considerably lower amounts of $\mathrm{K}^{+}$. In contrast, basal planes in fresh biotite are unaffected, and
TABLe 5: Pearson correlation matrix for biotite treated with acids and distilled water.

\begin{tabular}{lcccccc}
\hline Medium & & $\mathrm{F}^{-}$ & $\mathrm{K}^{+}$ & $\mathrm{Fe}^{2+}$ & $\mathrm{Na}^{+}$ & $\mathrm{Mg}^{2+}$ \\
\hline \multirow{5}{*}{ Citric } & $\mathrm{F}^{-}$ & 1 & & & & \\
& $\mathrm{~K}^{+}$ & 0.414 & 1 & & & \\
& $\mathrm{Fe}^{2+}$ & 0.544 & 0.565 & 1 & & \\
& $\mathrm{Na}^{+}$ & 0.580 & 0.009 & 0.352 & 1 & \\
& $\mathrm{Mg}^{2+}$ & 0.777 & 0.530 & 0.582 & 0.460 & 1 \\
\hline \multirow{6}{*}{$\mathrm{HNO}_{3}$} & $\mathrm{~F}^{-}$ & 1 & & & & \\
& $\mathrm{~K}^{+}$ & -0.222 & 1 & & & \\
& $\mathrm{Fe}^{2+}$ & -0.478 & 0.584 & 1 & & \\
& $\mathrm{Na}^{+}$ & 0.294 & -0.260 & -0.536 & 1 & \\
& $\mathrm{Mg}^{2+}$ & -0.221 & -0.146 & 0.033 & 0.137 & 1 \\
\hline \multirow{6}{*}{ Water } & $\mathrm{F}^{-}$ & 1 & & & & \\
& $\mathrm{~K}^{+}$ & 0.259 & 1 & & & \\
& $\mathrm{Fe}^{2+}$ & 0.043 & -0.054 & 1 & & \\
& $\mathrm{Na}^{+}$ & 0.538 & -0.145 & 0.104 & 1 & \\
& $\mathrm{Mg}^{2+}$ & 0.042 & -0.214 & -0.027 & 0.157 & 1 \\
\hline
\end{tabular}

they can carry higher amount of $\mathrm{K}^{+}$that is released in large quantities during the treatment.

$\mathrm{Fe}^{2+}$ is in the octahedral sites in the biotite structure $[1,25]$. Stability of $\mathrm{Fe}^{2+}$ in octahedral site in micas is fairly high compared to that in the octahedral site of weathering products of micas such as chlorite, vermiculite, and kaolinite $[26,27]$. However, several studies have indicated that octahedral cations (primarily $\mathrm{Mg}$ and $\mathrm{Fe}$ ) are preferentially released during biotite dissolution $[28,29]$, especially under acidic medium [17]. In the early stage, dissolution proceeds from the edges of crystals inward, and secondary minerals such as Fe oxide are precipitated mostly at the edges [24]. Accumulated iron oxide in weathered or moderately weathered mica can easily dissolve in both organic and inorganic acids that result in the presence of higher concentrations of iron in solutions in the initial stage and then continue releasing of $\mathrm{Fe}^{2+}$, but with lower concentrations, this may be attributed to boring into the octahedral sheet from the edge towards the interior [30]. Fresh biotite also released higher amount of $\mathrm{Fe}^{2+}$ in the first month as the acids can interact with the iron on the edges which contain more reactive sites [21]. The leached $\mathrm{Fe}^{2+}$ and $\mathrm{Al}^{3+}$ in the edges can produce iron and aluminum hydroxides which may have interfered with the further dissolution process [31]. That may also be ascribed to lower concentrations of $\mathrm{Fe}^{2+}$ in the later stages.

The behavior of $\mathrm{Na}^{+}$and $\mathrm{Mg}^{2+}$ under different acidic conditions or weathering stages is not systematic. It may be due to low availability of them or interferences from the early released ions such $\mathrm{Fe}^{2+}, \mathrm{K}^{+}$, and $\mathrm{Al}^{3+}$.

Hydroxyl group in the biotite structure occurs in the edges of the octahedral structure, and it is perpendicular to the tetrahedral sheets. The $\mathrm{H}$ of the $\mathrm{O}-\mathrm{H}$ bond is placed relatively closer to the interlayer cation. This orientation causes weakening of the strength of the interlayer bond. 
However, substitution of $\mathrm{F}^{-}$for $-\mathrm{OH}$ would presumably cancel this effect, increasing the interlayer bond strength [32]. This substitution causes no change in the trioctahedral structure, but the interlayer bond energy is increased [33] resulting in forming a stronger biotite structure. Therefore, the leaching of $\mathrm{F}^{-}$is difficult if it replaces the $\mathrm{OH}^{-}$group. However, this strong bond can be dissociated after releasing of cations as stability of $\mathrm{F}^{-}$depends also on the distribution of octahedrally coordinated cations $[34,35]$.

4.2. Influence of the Type of Acid on Leaching of $\mathrm{F}^{-}, \mathrm{K}^{+}$, and $\mathrm{Fe}^{2+}$. The dissolution of biotite in dilute $\mathrm{HNO}_{3}$ and water was studied previously $[20,23]$ and showed that the decreasing order for the short time leaching rates with dilute $\mathrm{HNO}_{3}$ is $\mathrm{Mn}>\mathrm{K}>\mathrm{Fe}, \mathrm{Al}>\mathrm{Mg}$, and $\mathrm{Ti}>\mathrm{Si}$. Also it was revealed that the precipitation occurred at the edges before releasing elements. Therefore, the rate of leaching of the above ions can be lowered with the time in the inorganic acidic or water mediums due to the precipitation that prevents further reactions.

The precise reactions between the biotite or its weathering products and organic acids are not known clearly although the organic acids are normal constituents of most of the soils [29]. Higher concentrations of leached ions from citric acid of the present study may be the result of the forming of complexes other than the acid attack as shown by Barman et al. [30]. Hendricks [36] showed that the organic ions are held by van der Waals forces in addition to coulombic forces. Therefore, larger ions are more strongly adsorbed because of the greater van der Waals forces. Citric acid is a large organic molecule with three carboxyl groups, and therefore, it acts as a polydentate ligand which has higher potential to leach out ions compared to strong inorganic acids. Also organic molecule can adsorb on biotite structure with the formation of ionic bonds between ionized carboxyl groups of the organic molecule and unsatisfied valence bonds of exposed ions. Therefore, adsorption can be increased by the presence of polyvalent exchange cations, probably by a bridging mechanism. Ultimately the leached ions from the biotite are adsorbed into the organic molecule, and it leads to prevent the precipitation of ions as hydroxides. Consequently, further dissolution of biotite can take place when the organic materials are available. Also the effect of the citric acid on the highly weathered biotite should be high as chelation can take place on the weaken structure of biotite, through surface adsorption and complex formation reactions [29].

$\mathrm{Fe}^{2+}, \mathrm{K}^{+}$, and $\mathrm{F}^{-}$concentrations in citric acid systems always show a strong positive correlation. But the ions released by biotite treated with other reagents do not show such correlation (Table 5). This indicates that complexes have been formed with the leached ions and organic materials. Further, marked increase of $\mathrm{F}^{-}$and $\mathrm{K}^{+}$with the time (Figure 1(d), 1(e), 1(f)) in biotite treated with citric acid also indicates the possible complexation process. In summary, it can be suggested that the rate of leaching of $\mathrm{F}^{-}$ in biotite depends on the leaching of other ions and their fixation into organic molecules.
Reference [35] showed that concentrations of dissolved ions in groundwater rich in organic acids are high compared to groundwater having low organic acids.

4.3. $F^{-}$Leaching from Organic-Acid-Poor Soils. Oxidation and reduction reactions play an important role in the geochemical processes that occur in soil and groundwater. The inorganic oxidation reactions such as sulfur oxidation, iron sulfide oxidation, nitrification, and manganese (II) oxidation can generate acidic conditions in soil as well as in groundwater. However, the present study implies that such acidifications which are inorganic may not have much influence on the liberation of $\mathrm{F}^{-}$from mica. In contrast, organic acids available in soil have higher ability for the same phenomenon.

\section{Conclusion}

Leaching of $\mathrm{F}^{-}$from biotite mica depends strongly on its weathering stage and organic acids but does not depend on the available inorganic acids. Ionic exchange between the biotite and organic acids and the formation of organic complexes may lead to the release of $\mathrm{F}^{-}$into the solutions. The structure of biotite can change due to the continuous interaction of citric acid which promotes for further leaching of fluoride into solutions.

It can be suggested that biotite mica in organic-acidrich soil leached readily fluoride into pore water or water percolates through the soil. Therefore, shallow groundwater may achieve high fluoride concentrations.

\section{References}

[1] W. A. Deer, R. A. Howie, and J. Zussman, An Introduction to the Rock-Forming Minerals, ELBS, Essex, UK, 2nd edition, 1992.

[2] H. A. Dharmagunawardhana, "Fluoride in Groundwater, Surface water, Rocks and Soils of an area of endemic fluorosis in the dry zone of Sri Lanka," in Proceedings of the 4th International Workshop on Fluorine Prevention and Defluoridation of Water, p. 7, 2004.

[3] Z. Li, Y. Tainosho, K. Shiraishi, and M. Owada, "Chemical characteristics of fluorine-bearing biotite of early Paleozoic plutonic rocks from the Sor Rondane Mountains, East Antarctica," Geochemical Journal, vol. 37, no. 2, pp. 145-161, 2003.

[4] D. K. Nordstrom, J. W. Ball, R. J. Donahoe, and D. Whittemore, "Groundwater chemistry and water-rock interactions at Stripa," Geochimica et Cosmochimica Acta, vol. 53, no. 8, pp. 1727-1740, 1989.

[5] H. Dong, D. R. Peacor, and S. F. Murphy, “TEM study of progressive alteration of igneous biotite to kaolinite throughout a weathered soil profile," Geochimica et Cosmochimica Acta, vol. 62, no. 11, pp. 1881-1887, 1998.

[6] R. A. Eggleton, "The relations between crystal structure and silicate weathering rate," in Rates of Chemical Weathering of Rocks and Minerals, Academic Press, London, UK, 1986.

[7] N. Madhavan and V. Subramanian, "Fluoride in fractionated soil samples of Ajmer district, Rajasthan," Journal of Environmental Monitoring, vol. 4, no. 6, pp. 821-822, 2002. 
[8] D. R. Boyle and M. Chagnon, "An incidence of skeletal fluorosis associated with groundwaters of the maritime carboniferous basin, Gaspé region, Quebec, Canada," Environmental Geochemistry and Health, vol. 17, no. 1, pp. 5-12, 1995.

[9] E. H. Oelkers, "General kinetic description of multioxide silicate mineral and glass dissolution," Geochimica et Cosmochimica Acta, vol. 65, no. 21, pp. 3703-3719, 2001.

[10] E. H. Oelkers and J. Schott, "An experimental study of enstatite dissolution rates as funcion of $\mathrm{pH}$, temperature, and aqueous $\mathrm{Mg}$ and $\mathrm{Si}$ concentration, and the mechanism of pyroxene/pyroxenoid dissolution," Geochimica et Cosmochimica Acta, vol. 65, no. 8, pp. 1219-1231, 2001.

[11] O. S. Pokrovsky and J. Schott, "Kinetics and mechanism of forsterite dissolution at $25^{\circ} \mathrm{C}$ and $\mathrm{pH}$ from 1 to 12 ," Geochimica et Cosmochimica Acta, vol. 64, no. 19, pp. 3313$3325,2000$.

[12] A. F. White and S. L. Brantley, "Chemical weathering rates of silicate minerals, an overview," in Chemical Weathering Rates of Silicate Minerals, Mineralogical Society of America, Charlotte, NC, USA, 1995.

[13] R. S. Arvidson and F. T. Mackenzie, "The dolomite problem: control of precipitation kinetics by temperature and saturation state," American Journal of Science, vol. 299, no. 4, pp. 257-288, 1999.

[14] O. S. Pokrovsky and J. Schott, "Kinetics and mechanism of dolomite dissolution in neutral to alkaline solutions revisited," American Journal of Science, vol. 301, no. 7, pp. 597-626, 2001.

[15] J. S. Tribble, M. J. Lane, R. S. Arvidson, and F. T. Mackenzie, "Crystal chemistry, and thermodynamic and kinetic properties of calcite, dolomite, apatite, and biogenic silica: applications to petrologic problems," Sedimentary Geology, vol. 95, no. 1-2, pp. 11-37, 1995.

[16] J. B. Acker and O. P. Bricker, "The influence of $\mathrm{pH}$ on biotite dissolution and alteration kinetics at low temperature," Geochimica et Cosmochimica Acta, vol. 56, no. 8, pp. 30733092, 1992.

[17] B. E. Kalinowski and P. Schweda, "Kinetics of muscovite, phlogopite, and biotite dissolution and alteration at $\mathrm{pH} \mathrm{1-4,}$ room temperature," Geochimica et Cosmochimica Acta, vol. 60, no. 3, pp. 367-385, 1996.

[18] W. E. Kline and H. S. Fogler, "Dissolution kinetics: the nature of the particle attack of layered silicates in HF," Chemical Engineering Science, vol. 36, no. 5, pp. 871-884, 1981.

[19] M. Malmström and S. Banwart, "Biotite dissolution at $25^{\circ} \mathrm{C}$ : the $\mathrm{pH}$ dependence of dissolution rate and stoichiometry," Geochimica et Cosmochimica Acta, vol. 61, no. 14, pp. 27792799, 1997.

[20] M. P. Turpault and L. Trotignon, "The dissolution of biotite single crystals in dilute $\mathrm{HNO} 3$ at $24^{\circ} \mathrm{C}$ : evidence of an anisotropic corrosion process of micas in acidic solutions," Geochimica et Cosmochimica Acta, vol. 58, no. 13, pp. 27612775, 1994.

[21] D. S. Fanning and V. Z. Keramidas, Minerals in Soil Environments, Soil Science Society of America, Madison, Wis, USA, 1977.

[22] T. H. N. G. Amaraweera, Genesis of pegmatites and uses of pegnatite mine waste as fertilizer, Matale district, Sri Lanka, M.phil. thesis, Postgraduate Institute of Science, University of Peradeniya, Peradeniya, Sri Lanka, 2009.

[23] T. Murakami, S. Utsunomiya, T. Yokoyama, and T. Kasama, "Biotite dissolution processes and mechanisms in the laboratory and in nature: early stage weathering environment and vermiculitization," American Mineralogist, vol. 88, no. 2-3, pp. 377-386, 2003.
[24] M. F. Brigatti and P. Davoli, "Crystal-structure refinements of $1 \mathrm{M}$ plutonic biotites," American Mineralogist, vol. 75, no. 3-4, pp. 305-313, 1990.

[25] K. P. Nicolini, K. C. Lombardi, W. H. Schreiner, I. Mazzaro, F. Wypych, and A. S. Mangrich, "Evidence of weathering stages of phyllosilicates from biotite/muscovite to kaolinite, probed by EPR spectroscopy," Journal of Mineralogy and Petrology, vol. 97, no. 1-2, pp. 139-144, 2009.

[26] B. Velde, Introduction to Clay Minerals, Chapman \& Hall, Cambridge, UK, 1992.

[27] R. J. Gilkes, R. C. Young, and J. P. Quirk, "The oxidation of octahedral iron in biotite," Clays and Clay Minerals, vol. 20, no. 5, pp. 303-315, 1972.

[28] M. A. Velbel, "Geochemical mass balances and weathering rates in forested watersheds of the southern Blue Ridge," American Journal of Science, vol. 285, no. 10, pp. 904-930, 1985.

[29] A. C. Gaur and R. P. Pareek, "Organic acids in soil during degradation of organic residues," Proceedings of the Indian National Science Academy Part B Biological Sciences, vol. 40, no. 1, pp. 68-76, 1974.

[30] A. K. Barman, C. Varadachari, and K. Ghosh, "Weathering of silicate minerals by organic acids. I. Nature of cation solubilisation,” Geoderma, vol. 53, no. 1-2, pp. 45-63, 1992.

[31] A. F. White and A. Yee, "Aqueous oxidation-reduction kinetics associated with coupled electron-cation transfer from ironcontaining silicates at $25^{\circ} \mathrm{C}$," Geochimica et Cosmochimica Acta, vol. 49, no. 5, pp. 1263-1275, 1985.

[32] J. L. Munoz, "F-OH and $\mathrm{Cl}-\mathrm{OH}$ exchange in micas with applications to hydrothermal ore deposits," Reviews in Mineralogy, vol. 13, no. 1, pp. 469-493, 1984.

[33] R. F. Geise, "Electrostatic energy models of micas," in Reviews in Mineralogy, vol. 13, pp. 105-144, Mineralogical Society of America, Charlotte, NC, USA, 1984.

[34] A. M. Kalinichenko, I. V. Matyash, T. P. Khomyak, and V. I. Palvlishin, "Distribution of octahedral cations in biotites according to the data of proton magnetic resonance," Geochemical International, vol. 12, no. 1, pp. 18-24, 1975.

[35] J. Sanz and W. E. E. Stone, "NMR study of micas. II. Distribution of $\mathrm{Fe}^{2+}, \mathrm{F}$ and $\mathrm{OH}^{-}$in the octahedral sheet of phlogopites," American Mineralogist, vol. 64, pp. 119-126, 1979.

[36] S. B. Hendricks, "Base exchange of the clay mineral montmorillonite for organic cations and its dependence upon adsorption due to van der Waals forces," The Journal of Physical Chemistry, vol. 45, no. 1, pp. 65-81, 1941. 

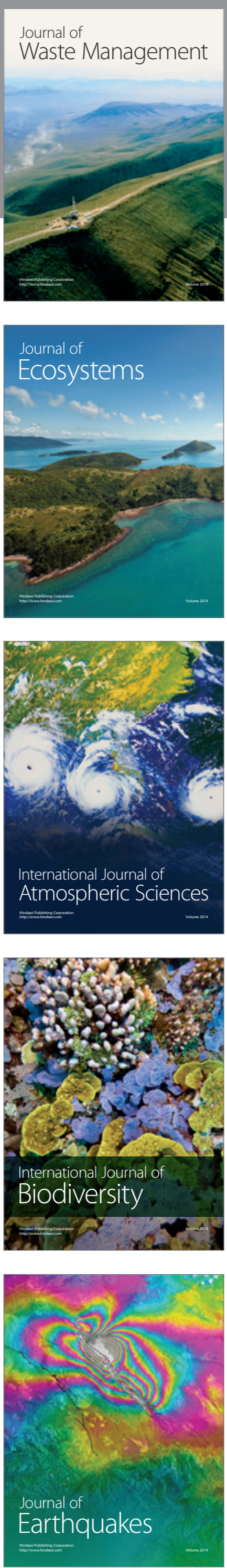
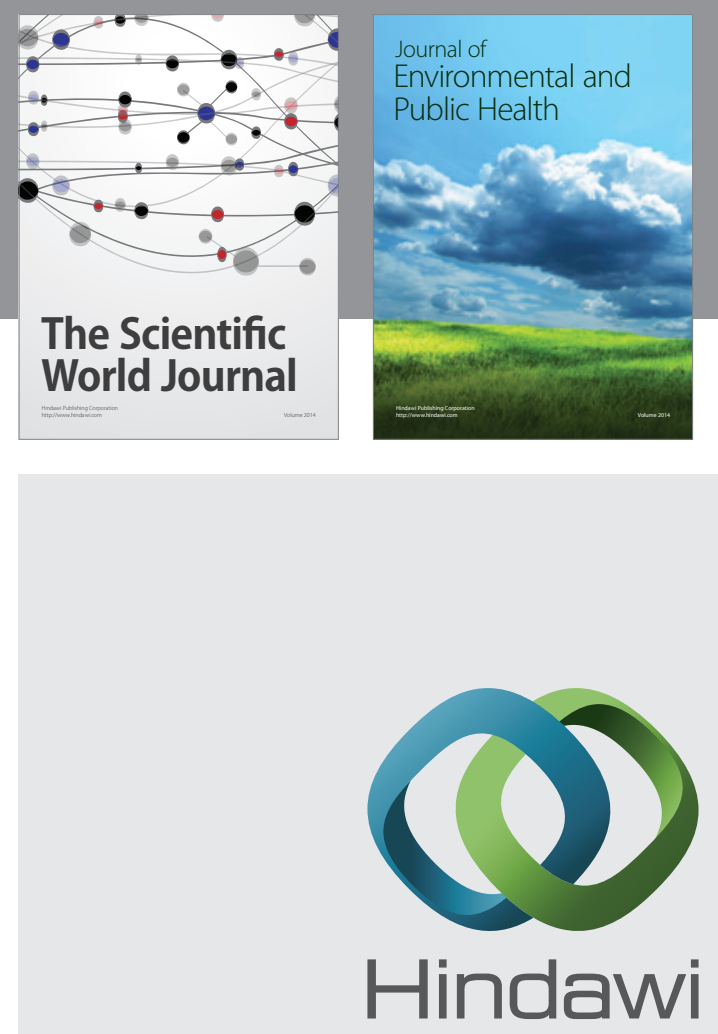

Submit your manuscripts at

http://www.hindawi.com
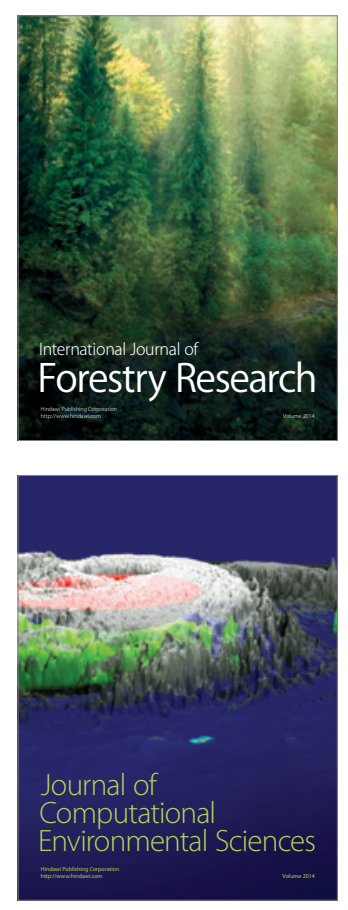
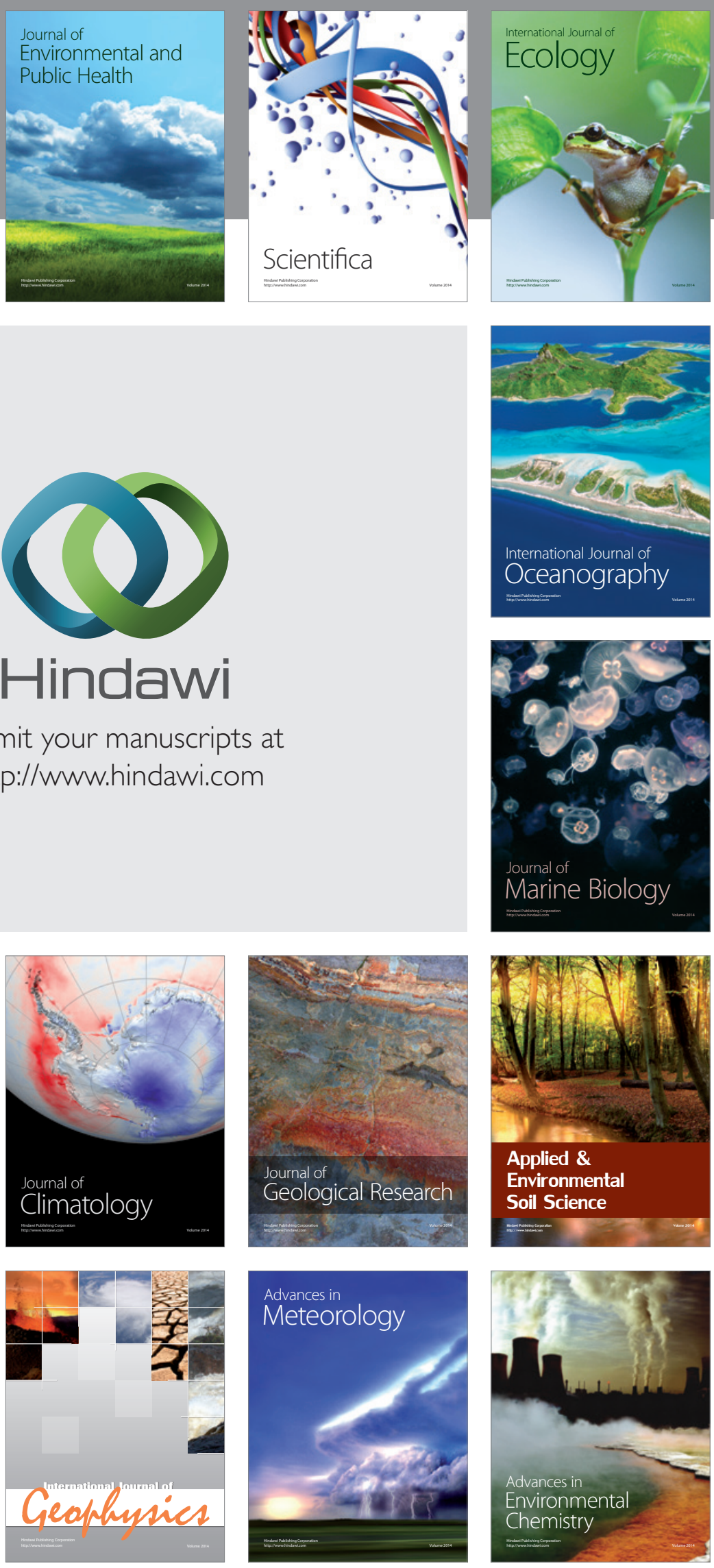